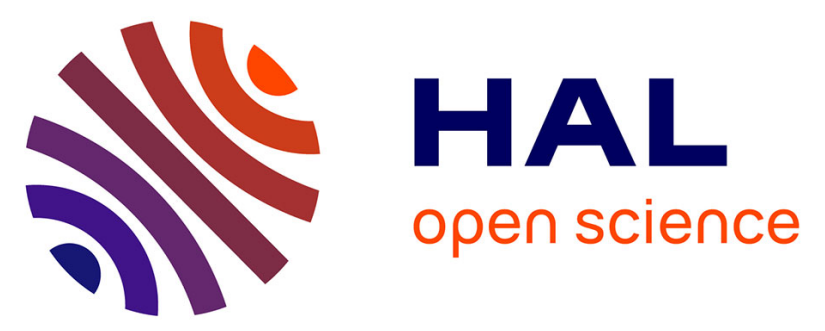

\title{
A multi-scale seismic response of two-dimensional sedimentary valleys due to the combined effects of topography and geology.
}

Behrouz Gatmiri, Solenn Le Pense, Pooneh Maghoul

\section{To cite this version:}

Behrouz Gatmiri, Solenn Le Pense, Pooneh Maghoul. A multi-scale seismic response of twodimensional sedimentary valleys due to the combined effects of topography and geology.. Journal of Multiscale Modeling, 2011, 3 (3), pp.133-149. 10.1142/S1756973711000455 . hal-00667869

\section{HAL Id: hal-00667869 \\ https: / hal-enpc.archives-ouvertes.fr/hal-00667869}

Submitted on 20 Feb 2013

HAL is a multi-disciplinary open access archive for the deposit and dissemination of scientific research documents, whether they are published or not. The documents may come from teaching and research institutions in France or abroad, or from public or private research centers.
L'archive ouverte pluridisciplinaire HAL, est destinée au dépôt et à la diffusion de documents scientifiques de niveau recherche, publiés ou non, émanant des établissements d'enseignement et de recherche français ou étrangers, des laboratoires publics ou privés. 
Electronic version of an article published as :

Journal of Multiscale Modelling, 03, 2011, pp 133-149

DOI: $10.1142 / \mathrm{S} 1756973711000455$

(C)World Scientific Publishing Compagny

http://www.worldscientific.com/worldscinet/jmm

\title{
A MULTI-SCALE SEISMIC RESPONSE OF TWO-DIMENSIONAL SEDIMENTARY VALLEYS DUE TO THE COMBINED EFFECTS OF TOPOGRAPHY AND GEOLOGY
}

\author{
B. GATMIRI \\ Department of Civil Engineering, University of Tehran, P.O. Box 11365-4563 \\ Tehran, Iran \\ ANDRA, Direction Scientifique, Parc de la Croix Blanche, 1-7 rue Jean Monnet \\ 92298 Chatenay-Malabry, France \\ Université Paris-Est, Laboratoire Navier (ENPC/IFSTTAR/CNRS), École des Ponts \\ ParisTech, 6 \& 8 Avenue Blaise Pascal, \\ 77455 Marne la Vallée, France \\ S. LE PENSE \\ Université Paris-Est, Laboratoire Navier (ENPC/IFSTTAR/CNRS), École des Ponts \\ ParisTech, $6 \& 8$ Avenue Blaise Pascal, \\ 77455 Marne la Vallée, France* \\ P. MAGHOUL \\ Université Paris-Est, Laboratoire Navier (ENPC/IFSTTAR/CNRS), École des Ponts \\ ParisTech, $6 \& 3$ Avenue Blaise Pascal, \\ 77455 Marne la Vallée, France
}

\begin{abstract}
It is well-known that the response of a site to seismic excitation depends on the local topographical and geological conditions. The current building codes already take into account unidimensional site effects but ignore complex site effects due to two-dimensional irregular configurations. The aim of this work is to contribute to the establishment of a simple predictive method to estimate site effects. The horizontal ground movements at the surface of sedimentary valleys subjected to SV waves with vertical incidence are calculated by using the HYBRID program, combining finite elements in the near field and boundary elements in the far field (FEM/BEM). A parametric study is conducted to examine the combined effects of topography and geology on the amplification of the response spectrum at various points across the valley. The influence of different parameters is considered, such as filling ratios (from empty to full valleys), impedance contrasts between bedrock and sediments, and dimensions.
\end{abstract}

Keywords: Seismic site effect; Seismic amplification; Building codes; Seismic response spectrum; Hybrid numerical method; Sedimentary valley; 2D configurations

*Université Paris-Est, Laboratoire Navier (ENPC/IFSTTAR/CNRS), École des Ponts ParisTech, 6 \& 8 Avenue Blaise Pascal, 77455 Marne la Vallée, France. solenn.le-pense@enpc.fr 


\section{Introduction}

It has been often observed that, after earthquakes, some buildings located on hills or in sedimentary basins suffer greater damage than might have been expected from their distance to the epicentre. The modification of the seismic movement due to local topographical and geotechnical conditions is called site effect.

Even though one-dimensional (1D) site effects have already been incorporated in current building codes, there is still progress to be made in taking into consideration complex site effects due to two-dimensional (2D) irregular configurations.

Much work has been done since the 1980s to improve the understanding of the physical phenomena involved in site effects and their prediction. Analytical solutions have been developed for simple configurations ${ }^{5,6,7,8,9}$. Simultaneously, experimental methods have been developed to make the most of in-situ measurements ${ }^{10}$.

More recently, the development of numerical methods has made it possible to study site effects for more complex configurations. Gatmiri and his coworkers have developed a program combining finite elements in the near field and boundary elements in the far field (FEM/BEM) called HYBRID ${ }^{3,4}$.

Gatmiri and Arson (2008) ${ }^{1}$ proposed a quantitative method to predict horizontal surface displacements. They used independent factors representing the contribution of different geometrical parameters controlling site effects.

Gatmiri et al. (2009) ${ }^{2}$ showed that in the central zone of a sedimentary valley, geological effects prevail upon topographical effects, whereas from the mid-slope point up to the edge of the valley topographical effects prevail in the site response. They also introduced a criterion for empty valleys, $S / A$ (Surface/Angle), with which the amplification at the top corner increases (Fig. 1).

Based on these previous studies, the aim of this work is to propose a simple criterion combining soil properties and geometrical characteristics, for estimating the amplification of earthquake response spectra in sedimentary valleys.

We computed horizontal displacements at the surface of sedimentary valleys by using the HYBRID code. A parametric study is conducted to evaluate the effects of various parameters on the amplification of the response spectrum. Calculations are made for several points at the surface of valleys (more than 20 points per valley).

The seismic solicitation is a vertically incident SV Ricker wave (Fig. 2).

In the following, soils are assumed to be dry and linearly elastic.

The predominant frequency of the incident signal is fixed and equal to $2 \mathrm{~Hz}$

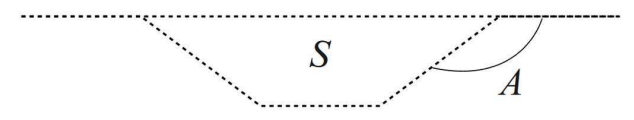

Fig. 1. Definition of parameter $S / A$ 
(Fig. 3).

The reference is taken as the scattering of the Ricker incident wave on a flat bedrock surface.

\section{Method}

A very common representation of seismic movement used by engineers is the response spectrum. This is a plot of the maximum response of a family of damped single-degree-of-freedom oscillators to earthquake ground motion. The pseudoacceleration response spectrum gives an estimation of the maximum acceleration at the base of the building as a function of the natural period of the oscillator Tn.

For each case, we calculate the earthquake response spectrum with $5 \%$ damping and compare it with the reference spectrum (Fig. 4). The spectral ratio, $S R$, is defined as the maximum ratio between the pseudo-acceleration $S A$ and the pseudoacceleration of the reference spectrum $S A_{R}$, for $T_{n}$ between 0.1 to 1 second. The site period, $T_{s}$, is defined as the natural period for which this ratio $S A / S A_{R}$ reaches its peak.

\section{1D site effects}

\subsection{Soil properties}

The mechanical parameters for sediments and bedrock are given in Table 1.

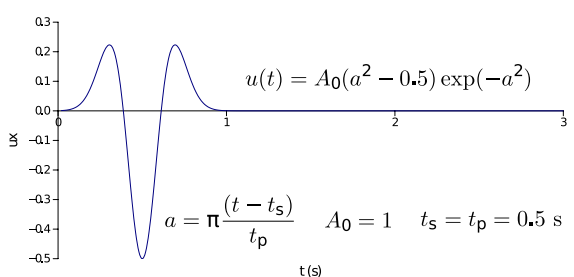

Fig. 2. Incident Ricker signal

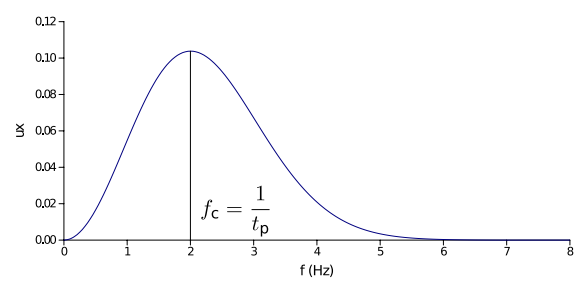

Fig. 3. Fourier transform of the reference displacement

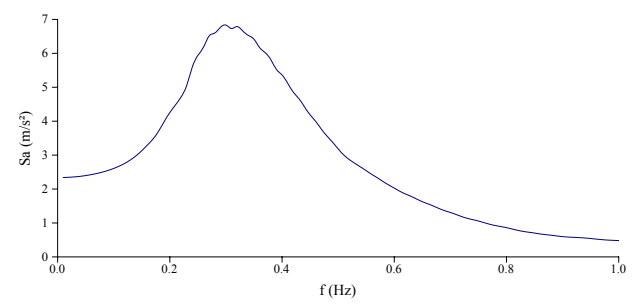

Fig. 4. Elastic acceleration response spectrum with $5 \%$ damping of the reference signal 
The impedance contrast between sediments and bedrock characterises the soil properties "Eq. (1)".

$$
\beta=\frac{\rho_{s} C_{s}}{\rho_{r} C_{r}}
$$

Table 1. Mechanical parameters of materials

\begin{tabular}{|l|c|c|c|c|c|c|c|}
\hline & $E(\mathrm{MPa})$ & $K(\mathrm{MPa})$ & $\nu$ & $G(\mathrm{MPa})$ & $\rho\left(\mathrm{T} / \mathrm{m}^{3}\right)$ & $C(\mathrm{~m} / \mathrm{s})$ & $\beta$ \\
\hline \hline Bedrock & 6720 & 11200 & 0.4 & 2400 & 2.45 & 990 & \\
\hline \hline \multirow{3}{*}{ Sediments } & 382 & 318 & 0.3 & 147 & 1.63 & 300 & $\mathbf{0 . 2}$ \\
\cline { 2 - 8 } & 899 & 750 & 0.3 & 346 & 1.63 & 461 & $\mathbf{0 . 3}$ \\
\cline { 2 - 8 } & 1527 & 1272 & 0.3 & 587 & 1.63 & 600 & $\mathbf{0 . 4}$ \\
\cline { 2 - 8 } & 2385 & 1988 & 0.3 & 917 & 1.63 & 750 & $\mathbf{0 . 5}$ \\
\hline
\end{tabular}

Note:

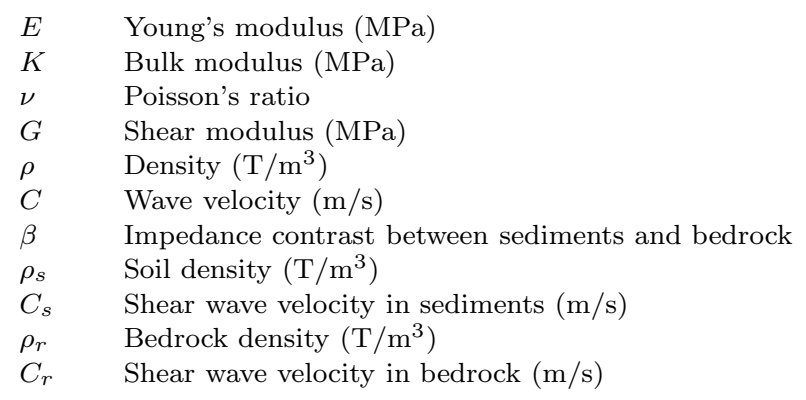

\subsection{Analytical solution}

In the first place, we consider the simple case of an horizontal soil layer over a semi-infinite elastic space submitted to an harmonic plane $\mathrm{S}$ wave. We know the analytical formula of the ratio between the displacements at the surface point A

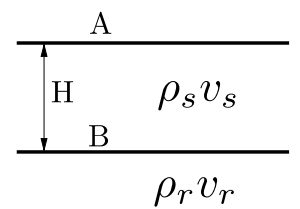

(a) Geometry

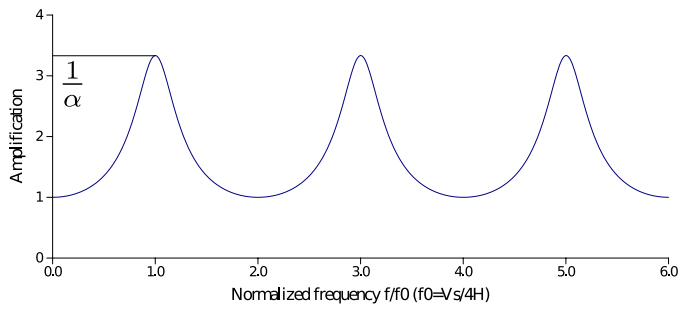

(b) Transfert function

Fig. 5. 1D site effect of a soil layer on a bedrock 
and at point B located at the interface between the soil layer and bedrock "Eq. (2)" (Fig. 5).

$$
\frac{u_{A}}{u_{B}}=\frac{1}{\sqrt{\cos ^{2}\left(k_{s} \cdot H\right)+\beta^{2} \cdot \sin ^{2}\left(k_{s} \cdot H\right)}}
$$

- $H$ is the soil layer height.

- $k_{s}=\frac{2 \pi f_{c}}{C_{s}}$ is the wavenumber where $C_{s}$ is the shear wave velocity in sediments and $f_{c}$ is the predominant frequency of the input signal.

- $\beta$ is the impedance contrast between sediments and bedrock.

The maximum amplification takes place for specific frequencies. "Eq. $(3,4)$ "

$$
\begin{gathered}
f_{n}=(2 n+1) \frac{C_{s}}{4 H} \\
\left(\frac{u_{A}}{u_{B}}\right)_{\max }=\frac{1}{\alpha}
\end{gathered}
$$

\subsection{Site period $T_{s}$}

We study the seismic response of horizontal soil layers with various heights and impedance contrasts. The height $H$ varies from $10 \mathrm{~m}$ to $100 \mathrm{~m}$ and the impedance contrast $\beta$ varies from 0.2 to 0.5 .

Concerning the site period, we notice that, when $H$ increases for a fixed $\beta, T_{s}$ first increases. If $H$ keeps increasing, $T_{s}$ goes back to lower periods (Fig. 6).

Similarly, when $\beta$ decreases for a fixed $H, T_{s}$ increases (Fig. 7).

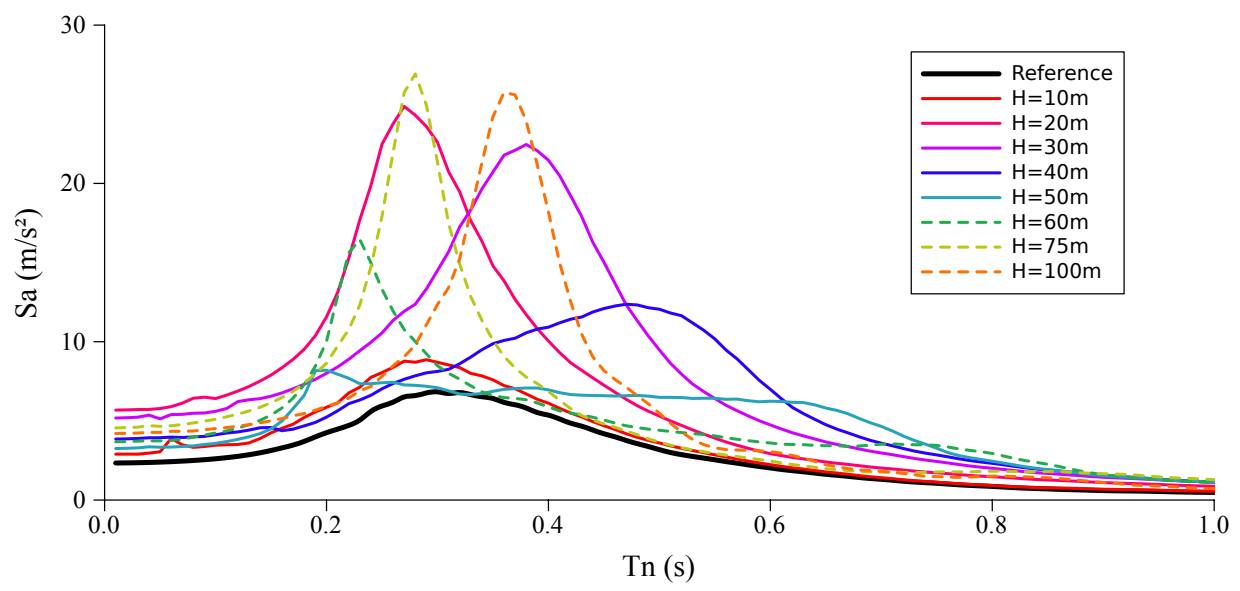

Fig. 6. Effect of height on response spectra $(\beta=0.2)$ 
If we suppose that the maximum amplification of the earthquake spectrum takes place for the natural period corresponding to the fundamental frequency of the soil layer, we obtain an analytical value of $T_{s}$ as a function of $H$ and $\beta$. "Eq. (5)"

$$
T_{s}=\frac{1}{f_{0}}=\frac{4 H}{C_{s}}=\frac{4 \rho_{s}}{\rho_{r} C_{r}} \frac{H}{\beta}=0.0027 \frac{H}{\beta}
$$

For cases for which the amplification is significant, Fig. 8 shows the evolution of $T_{s}$ with $H / \beta$ in comparison with the theoretical model $T_{s}=0.0027 H / \beta$

For values of $H / \beta$ from 65 to 300 , our set of data is very close to the theoretical

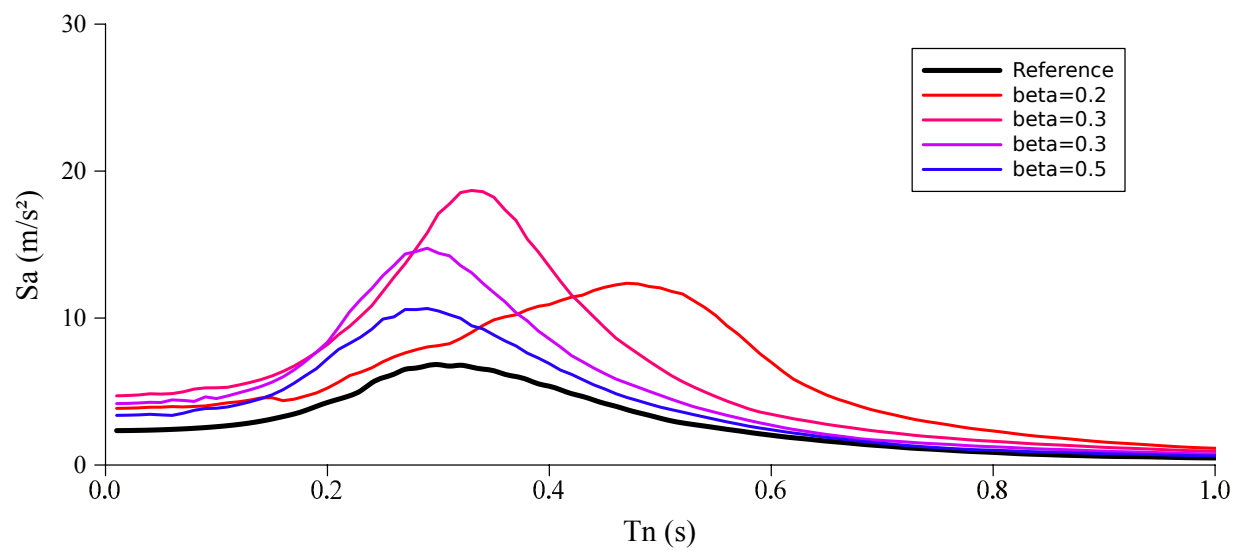

Fig. 7. Effect of impedance contrast on response spectra $(H=40 \mathrm{~m})$

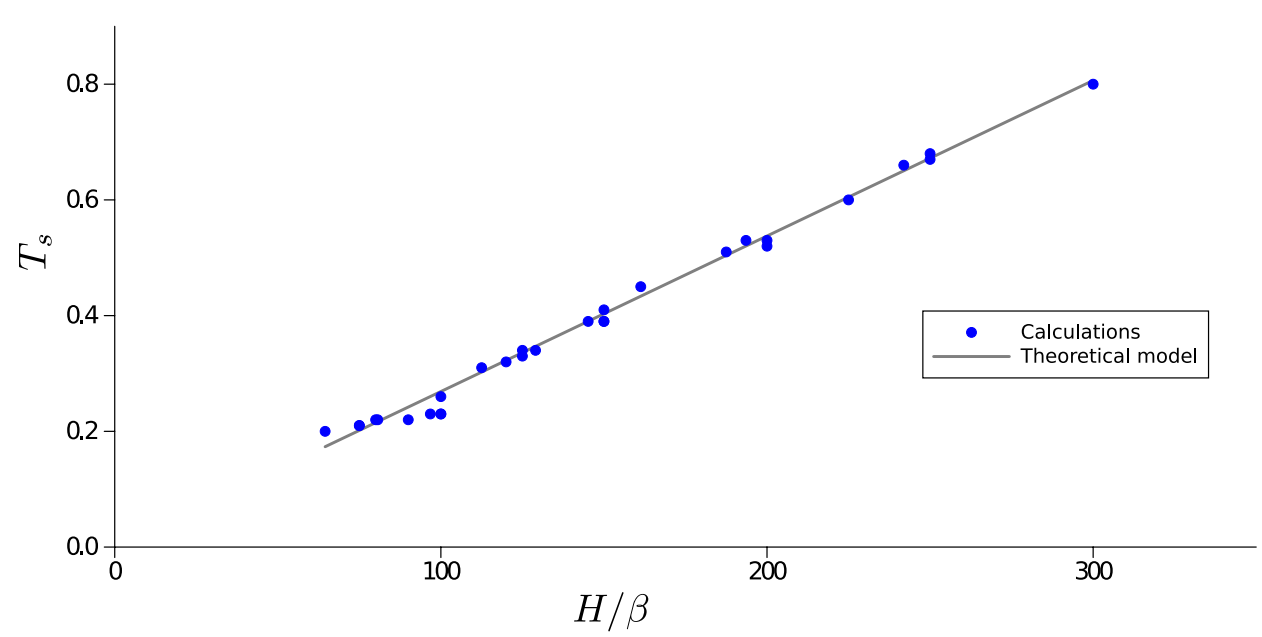

Fig. 8. Evolution of $T_{s}$ with $H / \beta$ 
model.

These values of $H / \beta$ correspond to soil layers with fundamental frequencies between 1.2 and $5.8 \mathrm{~Hz}$, which are the frequencies included into the incident signal (Fig. 3).

For higher frequencies (lower values of $H / \beta$ ) which are absent from the incident signal, the amplification is very weak. It does not allow us to determine an appropriate site period $T_{s}$.

Lower frequencies (higher values of $H / \beta$ ) correspond to the cases for which the site period $T_{s}$ goes back to low period, for high values of $H$ and low values of $\beta$. These frequencies being rare in the incident signal, this phenomenon may be due to a resonance of the soil layer on a second mode. From now on we will ignore these cases.

As can be seen in Fig. 8, the correlation between our data and the theory is good enough to validate our model.

\subsection{Spectral ratio}

For a constant site period $T_{s}$ the amplitude of response spectra decreases when $\beta$ increases (Fig. 9) and when $H$ increases (since these two parameters are linked by Eq. (5)).

We want to represent on the same graph the spectral ratios for the different soil layers, in order to give an estimation of the spectral ratio knowing $H$ and $\beta$.

We choose to represent the parameter $H / \beta$ which controls the site period $T_{s}$ on the x-axis, and the parameter $(S R-1) H$ on the y-axis (Fig. 10).

The parameter $(S R-1)$ allows us to visualise directly whether or not there is

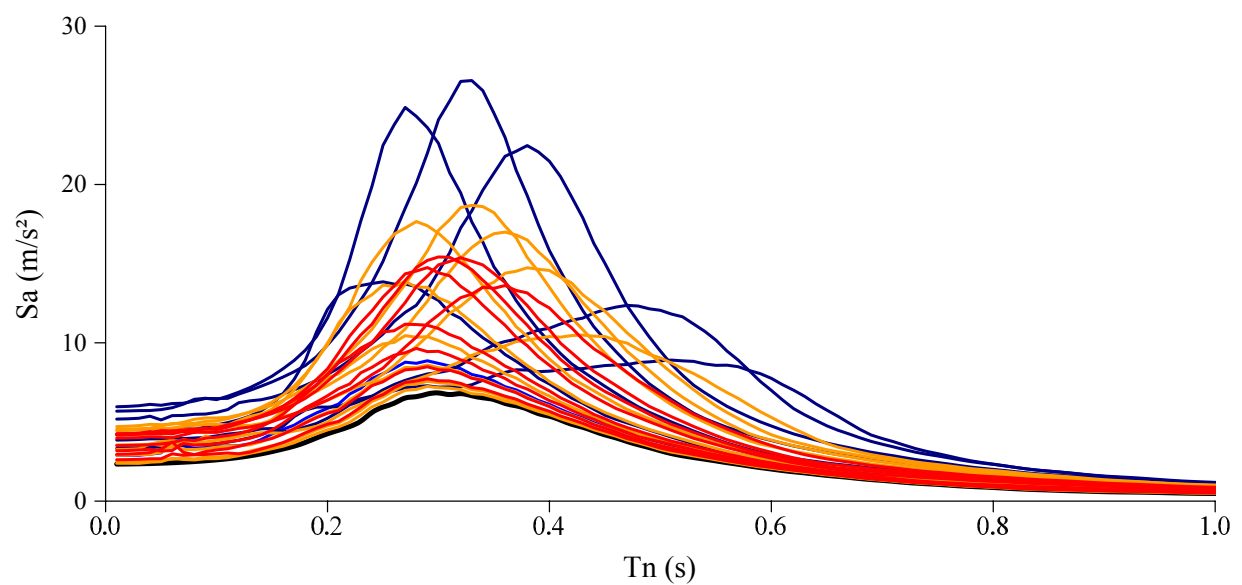

Fig. 9. Acceleration response spectra of $1 \mathrm{D}$ soil layers (Black: reference; blue: $\beta=0.2$; yellow: $\beta=0.3 ;$ red: $\beta=0.4$ 
an amplification. Indeed, when there is no amplification $S R-1=0$.

This parameter is then multiplied by $H$ to represent the fact that the spectral ratio decreases when $H$ increases for a given period.

\section{2D site effects}

\subsection{Geometrical characteristics}

The studied valleys are characterised by their half-width at the surface $L$, their half-width at the base $L_{1}$, their depth $H$ and the sediment layer height $H_{1}$. Let $A$ be the angle between the slope and the horizontal and $S_{1}$ the surface of the section filled with sediments (Fig. 11).

The half-width $L$ is equal to $100 \mathrm{~m}$. We study triangular valleys corresponding to $L_{1} / L=0$ and trapezoidal valleys corresponding to $L_{1} / L=0.4$. The calculations are made for different shape ratios $H / L=0.2,0.4,0.6,1$ and filling ratios $H_{1} / H=$ $0,0.25,0.5,0.75,1$.

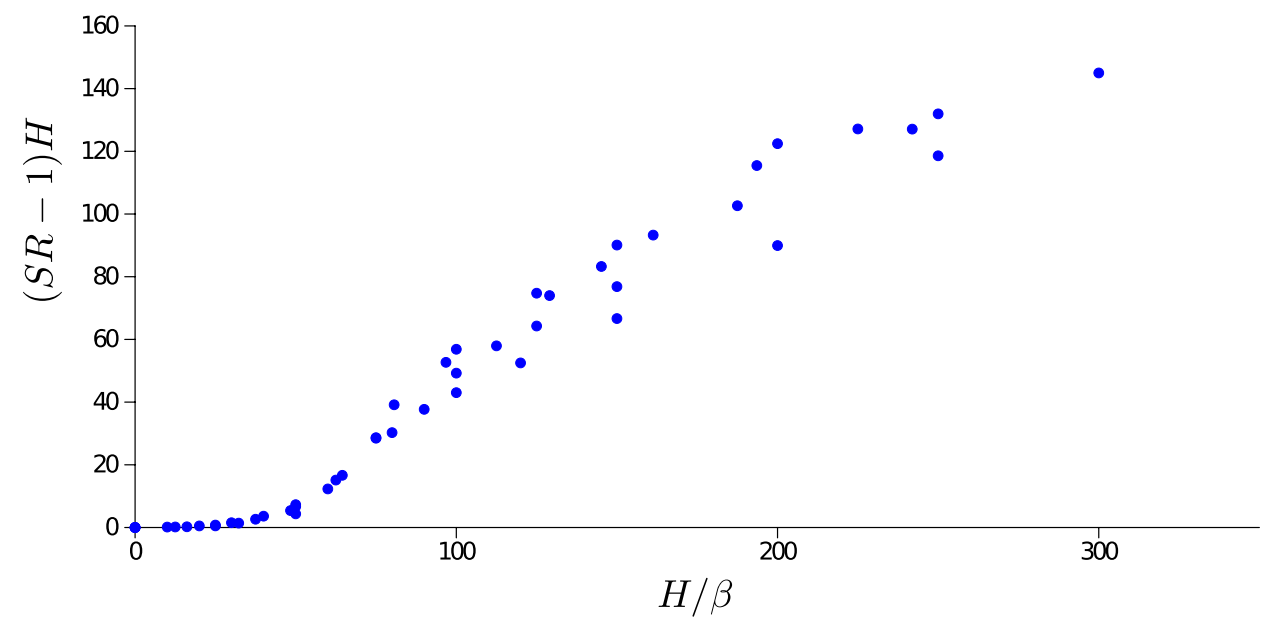

Fig. 10. Evolution of $(S R-1) H$ with $H / \beta$

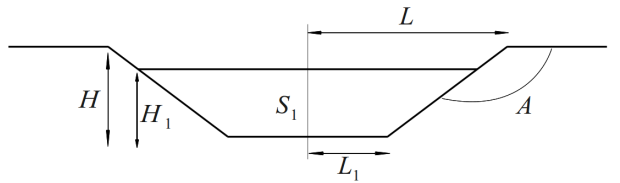

Fig. 11. Geometrical parameters 


\subsection{Spatial evolution}

First, we study the evolution of the spectral ratio with the spatial location of the studied point. The spectral ratio is represented as a function of the non-dimensional offset variable $x / L$ for different configurations.

By increasing the filling ratio, we go from empty valley behaviour with a maximum amplification at the edge of the valley to fully-filled valley behaviour with maximum amplification at the centre of the valley. For a quarter-filled valley the behaviour is the same as that of an empty valley (Fig. 12).

For intermediate filling ratios, there is a local maximum at the edge of the valley, a local maximum at the centre of the valley and a minimum at the contact point between sediments and bedrock. There is also a decrease of the spectral ratio by moving away from the valley (Fig. 13).

From now on, we will study those three specific points :

- Edge of the valley $(x / L=1)$

- Contact point sediments/bedrock

- Centre of the valley $(x / L=0)$

\subsection{Topographical effect, edge of the valley}

For empty valleys, the maximum amplification takes place at the edge of the valley. It increases with the shape ratio. Trapezoidal valleys entail higher amplifications than triangular valleys (Fig. 14 and 15).

Gatmiri et al. $(2009)^{2}$ proposed a criteria $S / A$ with which the spectral ratio at the edge increases (Fig. 1). Our numerical results follow this criteria (Fig. 16).

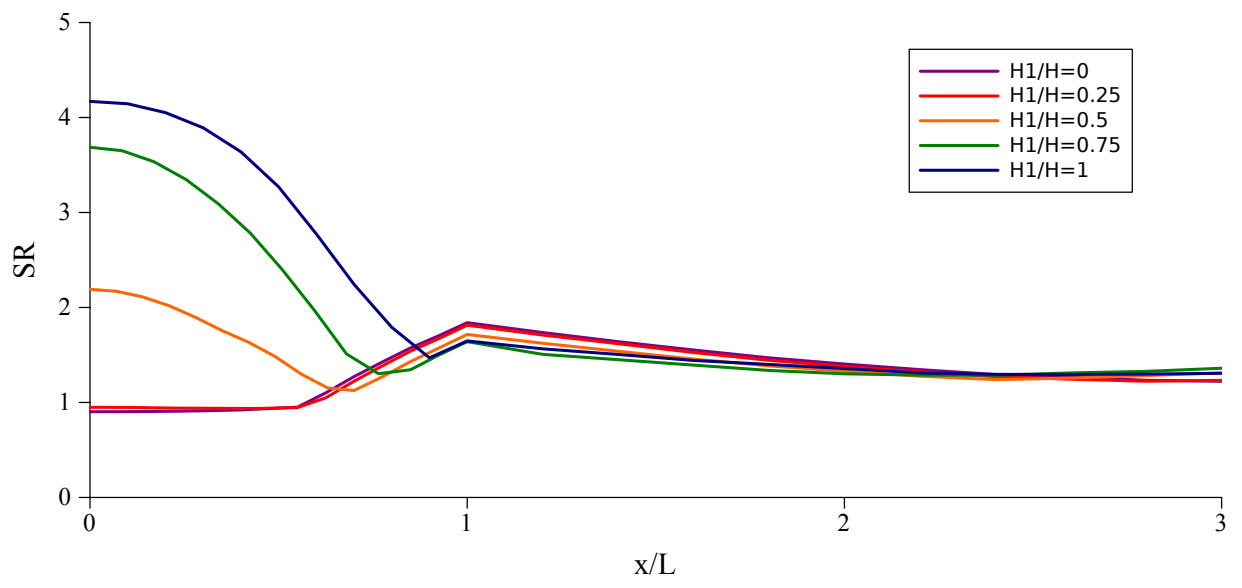

Fig. 12. Spatial evolution of spectral ratio for various filling ratios (trapezoidal valley with $H / L=$ 0.6 and $\beta=0.3$ ) 
We also notice that the spectral ratio at the edge is higher for empty valleys compared to partially-filled ones (Fig. 12). This is verified for every dimension and geometry of valleys and soil properties.

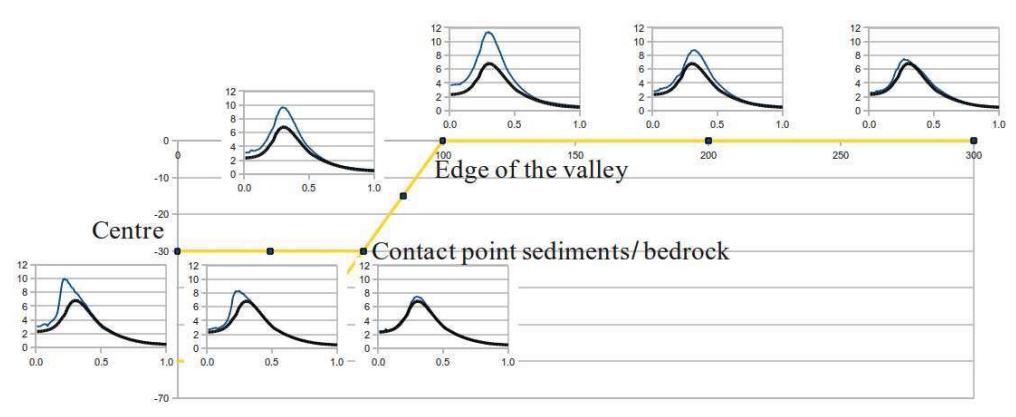

Fig. 13. Response spectrum evolution along a trapezoidal valley $\left(H / L=0.6, H_{1} / H=0.5, \beta=0.3\right)$ (Reference spectrum in black)

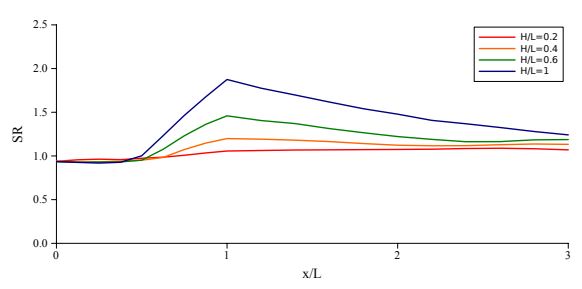

Fig. 14. Triangular empty valleys

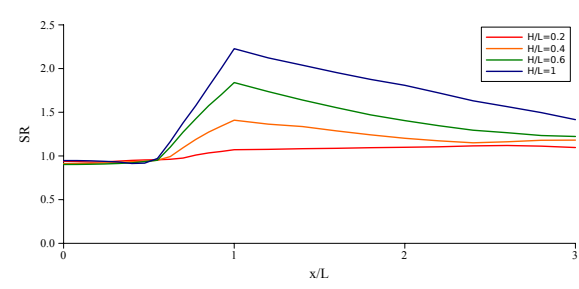

Fig. 15. Trapezoidal empty valleys

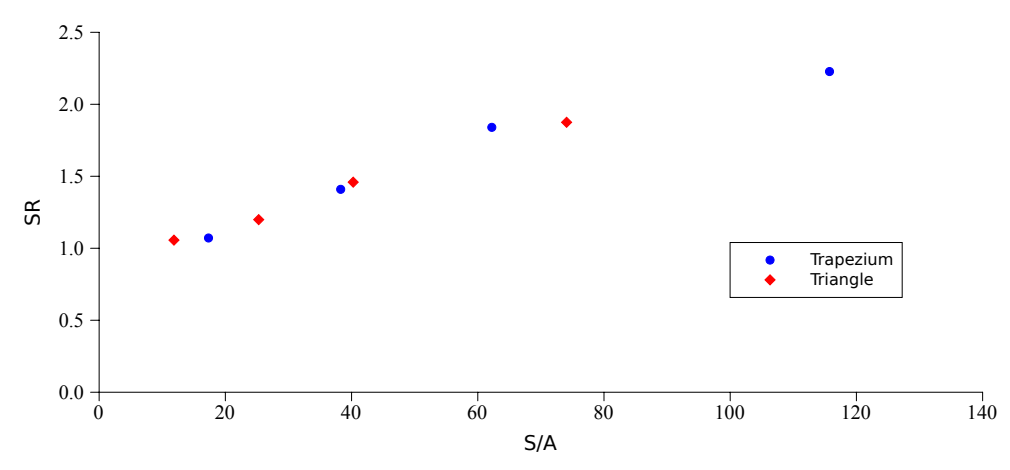

Fig. 16. Evolution of spectral ratio at the edge with $S / A$ for empty valleys 


\subsection{Contact point sediments/bedrock}

At the contact point between sediments and bedrock of partially-filled valleys, the spectral ratio is always lower than that of the corresponding empty valley with the same dimensions. It means that from this point up to the edge of the valley, topographical effects prevail upon geological effects. So, for points which are located on the rock (i.e. outside the area filled with sediments), it is possible to consider only the topographical site effect due to an empty valley. The response spectra calculated by this method will always be higher than the ones of the real cases.

We verify that the response spectra at this specific point of deep or shallow, fully or quarterly-filled valleys are lower than the ones of equivalent empty valleys

(Fig. 17, 18, 19 and 20)

\subsection{Centre of the valley}

\subsubsection{Envelope of response spectra}

For the different configurations, all the acceleration response spectra calculated at the central point of the valleys are represented on the same graph (Fig. 21).

If there is an attenuation of some spectra for low periods due to topographical effect, it is not significant compared to the amplification of other spectra. So, we will not study the attenuation cases afterwards.

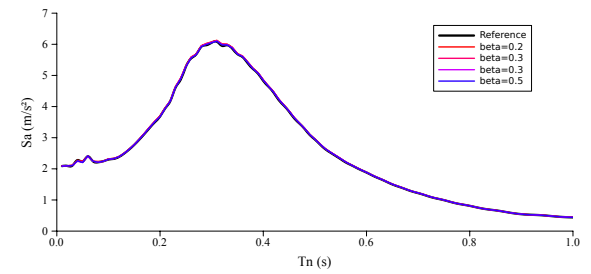

Fig. 17. $H_{1} / H=0.25, H / L=0.2, x / L=$ 0.55

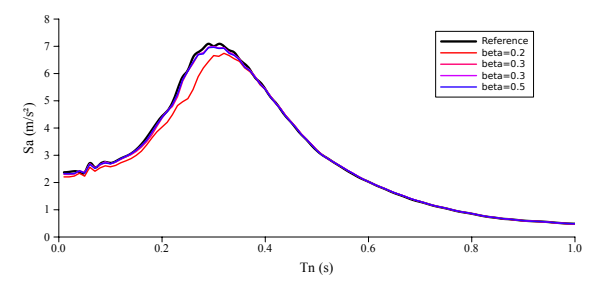

Fig. 19. $H_{1} / H=1, H / L=0.2, x / L=1$

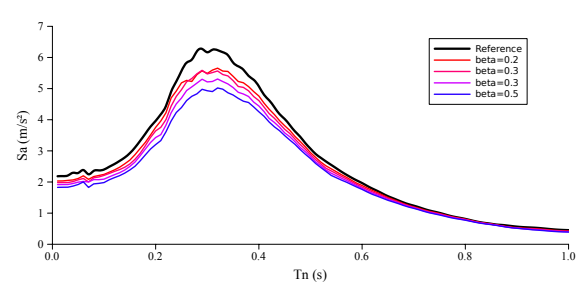

Fig. 18. $H_{1} / H=0.25, H / L=1, x / L=0.55$

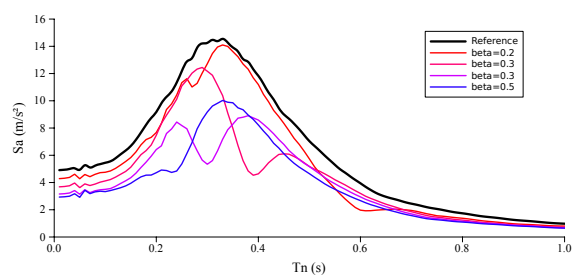

Fig. 20. $H_{1} / H=1, H / L=1, x / L=1$ 


\subsubsection{Site period}

Following the same method as for 1D soil layers, we want to define a criterion allowing an estimation of the site period for configurations with a significant amplification.

We propose to study the evolution of the site period with the parameter $S_{1} / \beta \sqrt{\beta}$ which combines the soil properties $(\beta)$ and the geometrical characteristics $\left(S_{1}\right)$ (Fig. $22)$.

An example of values taken by $S_{1} / \beta \sqrt{\beta}$ are given in Table 2 .

Table 2. Values taken by $S_{1} / \beta \sqrt{\beta}$ for trapezoidal valleys with different shape ratios and filling ratios, $\beta=0.3$

\begin{tabular}{c|c|c|c|c|}
\hline $\boldsymbol{H}(\mathrm{m})$ & & & \\
\hline 20 & 2,752 & 6,373 & 10,863 & 16,222 \\
\hline 40 & 5,504 & 12,746 & 21,726 & 32,445 \\
\hline 60 & 8,256 & 19,119 & 32,590 & 48,667 \\
\hline 100 & 3,621 & 14,484 & 32,590 & 57,937 \\
\hline
\end{tabular}

We study the case for which $13000<S_{1} / \beta \sqrt{\beta}<120000$

For $S_{1} / \beta \sqrt{\beta}<13000$ the amplification is not significant enough to determine a representative site period $T_{s}$.

For $S_{1} / \beta \sqrt{\beta}>120000$, we ignore the case corresponding to $H / L=1, \beta=0.2$, $H_{1} / H=1$ and $\beta \sqrt{\beta}=156000$ for which the site period goes back to low periods.

We observe a linear evolution of $T_{s}$ with $S_{1} / \beta \sqrt{\beta}$ (Fig. 22).

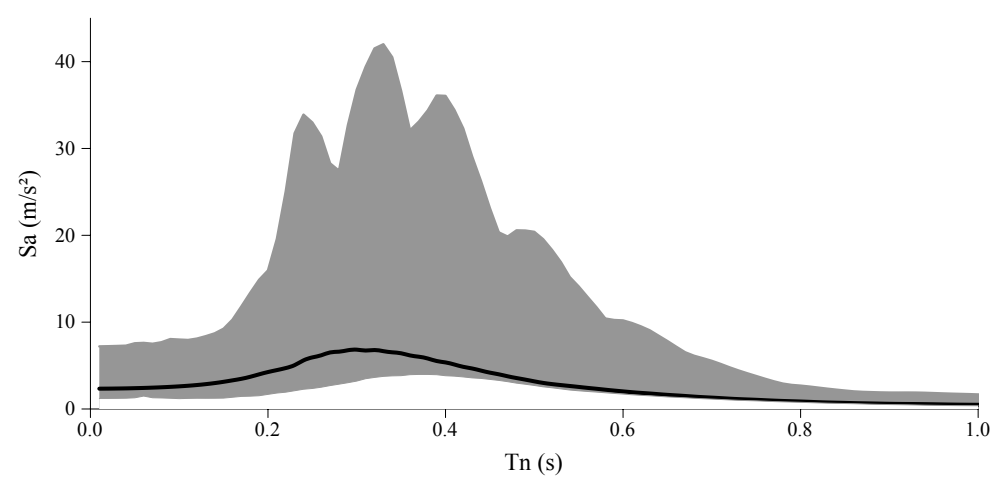

Fig. 21. Envelope of response spectra at the centre of the valley for various geometrical characteristics and soil properties. Black line is the reference spectrum 


\subsubsection{Spectral ratio}

As for 1D soil layers, we observe that, for a same period, spectra have a higher amplitude for soft soils ( low $\beta$ ) (Fig. 23 and 24).

By analogy with the 1D case we propose a representation of $(S R-1) S_{1}$ as a function of the parameter $S_{1} / \beta \sqrt{\beta}$ governing the site period. For triangular and trapezoidal valleys our numerical results are represented on Fig. 25. We eliminated one case $\left(H / L=1, \beta=0.2, H_{1} / H=1, S_{1} / \beta \sqrt{\beta}=156000\right)$ for which the site period goes back to low periods.

The amplification is negligible up to a threshold corresponding to $S_{1} / \beta \sqrt{\beta}=$ 13 000. Afterwards, the evolution of $(S R-1) \cdot S_{1}$ with $S_{1} / \beta \sqrt{\beta}$ shows a parabolic tendency.

From these curves, knowing the geometrical characteristics of the valley $S_{1}$ and

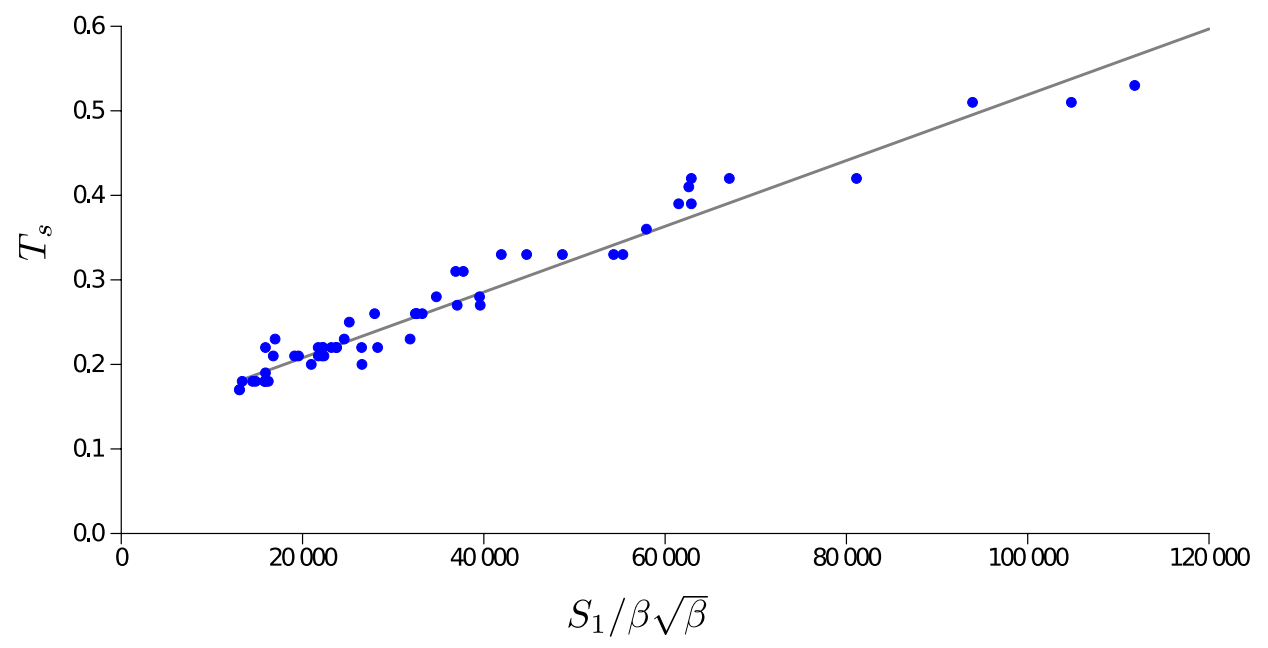

Fig. 22. Evolution of the site period with $S_{1} / \beta \sqrt{\beta}$ for trapezoidal and triangular valleys

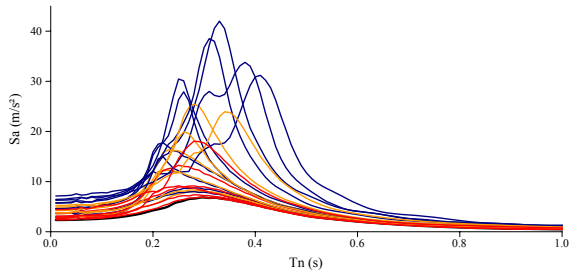

Fig. 23. Response spectra for triangular valleys (black: reference, blue: $\beta=0.2$, yellow: $\beta=0.3$, red: $\beta=0.4$ )

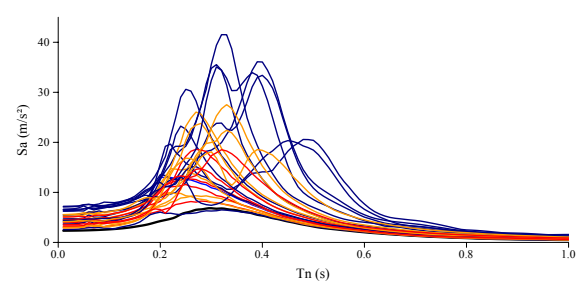

Fig. 24. Response spectra for trapezoidal valleys (black: reference, blue: $\beta=0.2$, yellow: $\beta=0.3$, red: $\beta=0.4$ ) 
its soil properties $\beta$, we can now calculate the coefficient $S_{1} / \beta \sqrt{\beta}$. With this coefficient we can read an estimation of the site period $T_{s}$ and the coefficient $(S R-1) \cdot S_{1}$ and then deduce the value of the spectral ratio $S R$ ( Fig. 22 and Fig. 25).

\section{Conclusions}

Although 2D complex site effects are not yet taken into consideration in building codes, many studies have pointed out the importance of their impact on seismic movement. Indeed, this site effects often leads to a higher amplification of the seismic signal compared to the $1 \mathrm{D}$ case. It also causes an extension of the signal length.

This study gives a method to characterise the spectral amplification of bidimensional triangular and trapezoidal valleys with various filling ratios. We considered valleys with shape ratios $H / L$ lower than 1 and impedance contrast higher than 0.2 .

We first found again known results :

- For 1D soil layers we found a good correlation with the analytical solution. Indeed, the maximum amplification of the acceleration response spectrum occurs for the natural period corresponding to the fundamental frequency of the soil layer.

- For empty valleys, the maximum amplification occurs at the edge of the valley and increases with the criteria $S / A$.

- In fully-filled valleys, the maximum amplification takes place at the centre of the valley.

- When increasing the filling ratio, we go from empty valley behaviour to fully-filled valley behaviour.

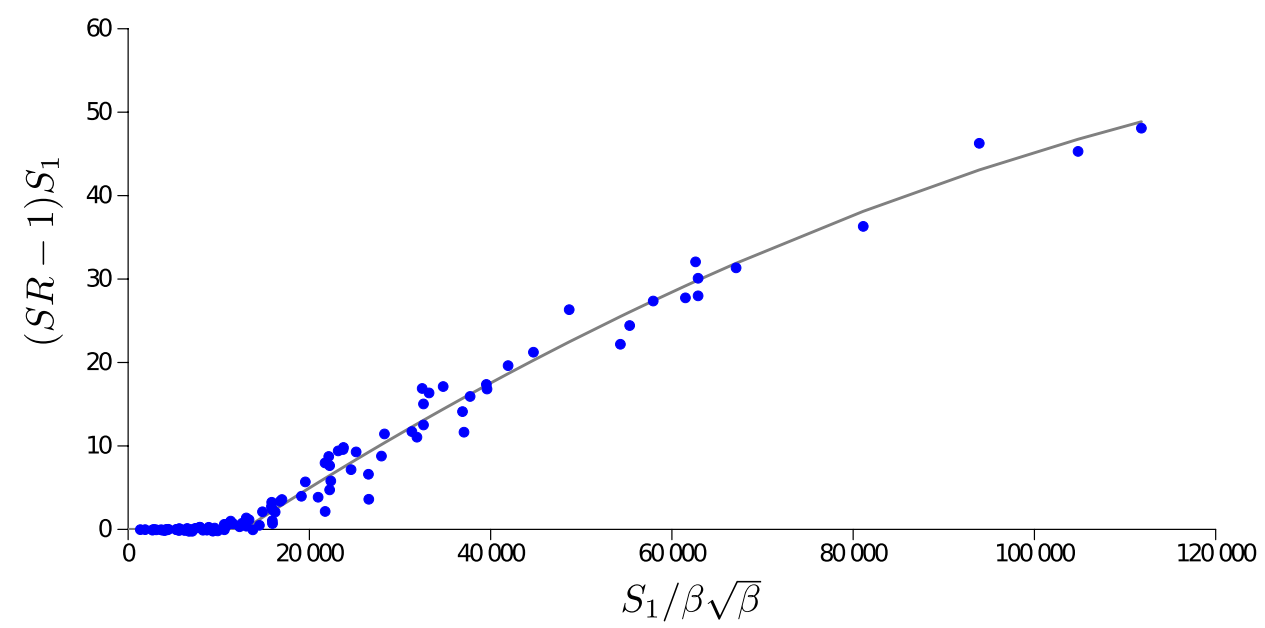

Fig. 25. Evolution of $(S R-1) \cdot S_{1}$ with $S_{1} / \beta \sqrt{\beta}$ 
The main results of this study are :

- In an alluvial valley, fully- or partially-filled with sediments, from the contact point between sediments and bedrock up to the edge and outside of valleys, topographical effects prevail upon geological effects.

- At the central point of the valley, the evolution of the site period $T_{s}$ with the parameter $S_{1} / \beta \sqrt{\beta}$ has a linear tendency. This parameter combines the soil properties and the geometrical characteristics of the valley.

- At the centre of the valley we can estimate the spectral ratio $S R$ from the curve representing the evolution of $(S R-1) S_{1}$ as a function of $S_{1} / \beta \sqrt{\beta}$ (Fig. 25).

\section{Appendix A. Appendices}

\section{References}

1. B. Gatmiri and C. Arson, Seismic site effects by an optimized 2D BE/FE method II. Quantification of site effects in two-dimensional sedimentary valleys, Soil Dyn. Earthquake Eng. 28, 646-661 (2008).

2. B. Gatmiri , P. Maghoul and C. Arson, Site-specific spectral response of seismic movement due to geometrical and geotechnical characteristics of sites, Soil Dyn. Earthquake Eng. 29 51-70 (2009).

3. B. Gatmiri and M. Kamalian, Two-dimensional transient wave propagation in anelastic saturated porous media by a Hybrid FE/BE method, Proc. 5th European Conf. on Numerical Methods in Geotechnical Engineering 947-956 (2002).

4. B. Gatmiri and K. Dehghan, Applying a new fast numerical method to elasto-dynamic transient kernels in HYBRID wave propagation analysis, Proc. 6th Conf. on on structural dynamics (EURODYN 2005) p. 1879-1884.

5. M.D. Trifunac, Surface motion of a semi-cylindrical alluvial valley for incident plane SH waves, Bull. Seismol. Soc. Am. 61(6) 1755-1770 (1971).

6. M.D. Trifunac, Scattering of plane SH waves by a semi-cylindrical canyon, Earthquake Eng. Struct. Dyn. 1(3) 267-281 (1972). title=Scattering of plane sh waves by a semicylindrical canyon,

7. H.L. Wong and M.D. Trifunac, Scattering of plane SH waves by a semi-elliptical canyon, Earthquake Eng. Struct. Dyn. 3(2) 157-169 (1974).

8. H.L. Wong and M.D. Trifunac, Surface motion of a semi-elliptical alluvial valley for incident plane SH waves, Bull. Seismol. Soc. Am. 64(5) 1389-1408 (1974).

9. F.J. Sanchez-Sesma, Diffraction of elastic SH waves by wedges, Bull. Seismol. Soc. Am. 75(5) 1435-1446 (1985).

10. Y. Nakamura, A method for dynamic characteristics estimation of subsurface using microtremor on the ground surface, Railway Technical Research Institute, Quarterly Reports 30 25-33 (1989). 